\title{
Laparoscopy in Abdominal Trauma
}

\author{
Orhan Veli Ozkan $^{1,3} \cdot$ Viktor Justin $^{2,3} \cdot$ Abe Fingerhut $^{3} \cdot$ Selman Uranues $^{3}$
}

Published online: 19 November 2016

(C) Springer International Publishing AG 2016

\begin{abstract}
Purpose of Review Exploratory laparotomy is the traditional therapeutic approach in patients with abdominal trauma. However, due to potential associated morbidity and mortality, avoiding unnecessary laparotomies is an important issue. Recent Findings While selective nonoperative management has shown good results, certain clinical situations in hemodynamically stable patients, where the need for surgery could be in doubt, call for proactive diagnosis. In these cases, laparoscopy can be used to exclude or diagnose potential injuries requiring surgery. When the surgeon has the necessary expertise, some of these injuries can be treated laparoscopically. Summary Over the last decades, diagnostic and therapeutic applications of laparoscopy have increased, with reported reduction in nontherapeutic laparotomies. Furthermore, shorter
\end{abstract}

This article is part of the Topical Collection on Minimally Invasive Surgical Techniques for Trauma

Orhan Veli Ozkan

veliorhan@hotmail.com

Selman Uranues

selman.uranues@medunigraz.at

Viktor Justin

viktor.justin@gmail.com

Abe Fingerhut

abefingerhut@aol.com

1 Department of General Surgery, Faculty of Medicine, Sakarya University, Sakarya, Turkey

2 Hospital of Saint Elisabeth, Vienna, Austria

3 Section for Surgical Research, Department of Surgery, Medical University of Graz, Auenbruggerplatz 29, 8036 Graz, Austria duration of hospital stay, faster recovery, and reduced costs have been reported. However, as seen in other minimally access interventions, safe implementation of laparoscopy in trauma care requires adequate surgical training and skills as well as appropriate staffing and equipment.

Keywords Abdominal trauma $\cdot$ Penetrating abdominal injury $\cdot$ Blunt abdominal injury $\cdot$ Negative laparotomy . Diagnostic laparoscopy $\cdot$ Therapeutic Laparoscopy

\section{Introduction}

Trauma is the leading cause of mortality in patients under 35 years worldwide [1] and poses a major challenge to health care providers. Although geographical variations exist, blunt trauma accounts for 78.9 to $95.6 \%$ of injuries around the globe [2-5]. Between 9 and $14.9 \%$ of all trauma cases involve the abdomen $[2,4]$. Laparotomy is the standard approach for abdominal trauma but is associated with morbidity ranging from 20 to $22 \%$ [6, 7] to $41.3 \%$ [8], particularly when explorative laparotomy is negative.

With increasing conservative, nonoperative management (NOM) policies [9, 10], technical developments in imaging, and advances in surgical techniques, the rate of negative and therefore unnecessary laparotomy has been reduced. Laparoscopy in trauma can potentially further decrease the negative laparotomy rate [11]. Proposed as early as 1925 [12], the initial experiences with laparoscopy in abdominal disorders and trauma date from the 1960s $[13,14]$ and laparoscopy then made its way into clinical practice. Since, a steadily rising amount of data and experience has been generated, showing the adequacy of laparoscopy in selected patient groups, primarily as a diagnostic tool but also as a therapeutic measure. 
The aim of this article is to review and highlight the current use and indications of laparoscopy in abdominal trauma.

\section{Management of Abdominal Trauma}

The management of abdominal trauma has evolved over the last decades, mainly driven by the goal of reducing additional iatrogenic aggression to the initial trauma. Several guidelines and recommendations for the management of abdominal trauma have been published over the last years: these include evidence-based approaches combining clinical examination, diagnostic tools, and operative measures both in blunt and penetrating abdominal trauma [15•, 16-18].

Initial assessment of abdominal trauma consists in proper anamnesis including trauma mechanism and clinical examination, aiming for quick identification of possible injuries. However, physical examination may be unreliable. Concomitant head trauma, changes in consciousness due to substance abuse, accompanying spinal trauma and absence of clinical signs, notably in retroperitoneal injuries, are confounding factors. After clinical examination, additional diagnostic tests may be required to determine injury characteristics and immediate need for surgery or not.

In penetrating trauma, local wound exploration (LWE) can be used for exclusion of peritoneal penetration. This is essential for further diagnostic and interventional steps, as patients without penetration of the peritoneal cavity may be discharged safely $[15 \bullet, 19]$. However, LWE has to be performed meticulously, as simple probing may lead to falsenegative results [20]. Especially in obese patients, diagnostic laparoscopy may provide more reliable results in determining peritoneal penetration $[21,22]$.

Diagnostic peritoneal lavage (DPL) has been described as cost-effective and easy to perform. In a systematic review, Catre reported a mean sensitivity of $98 \%$ (range from 90 to $100 \%$ ) with a specificity of $92 \%$ (range from 73 to $100 \%$ ) [23] for DPL. DPL usually is considered positive when the red blood cell (RBC) count is greater than $5000 / \mathrm{mm}^{3}$ in the lavage fluid [15•], although one article suggested a higher threshold of $10,000 / \mathrm{mm}^{3}$ to reduce nontherapeutic interventions [24]. In fact, according to Wood and colleagues, the high sensitivity and relatively low specificity might contribute to unnecessary exploratory operations in about 15 to $20 \%$ of patients [25].

Abdominal and thoracic X-rays can be used to screen for free abdominal air and diaphragmatic injuries, as well as determination of the trajectory in gunshot wounds (GSWs) by marking the entrance and exit wounds with radiopaque material [15•].

Focused assessment with sonography for trauma (FAST) is a relatively simple bedside screening tool for detection of abdominal free fluid and pericardial effusion both in penetrating and blunt trauma. However, apart from being - as is sonography in general-operator dependent, sensitivity is significantly lower than in DPL. Reported sensitivity rates range from 21 to $83.3 \%$, whereas specificity is reported to be 94 to $99.7 \%$ [26-28]. In their study on anterior abdominal stab wounds (SWs), Biffl et al. reported that $19 \%$ of their patients had to undergo a therapeutic laparotomy after initial negative FAST [19]. Therefore, a positive FAST can be seen as a strong predictor for abdominal injury, whereas negative results should be followed by further clinical or radiological assessment [28].

Computed tomography (CT) has high overall sensitivity and specificity [29, 30] in detecting abdominal abnormalities. Holmes et al. described a $0.3 \%$ missed intra-abdominal injury rate after blunt trauma [31]. In abdominal GSW, sensitivity and specificity were reported to be 90.5 and $96 \%$, respectively [32]. However, drawbacks have been described in diagnosing several specific conditions following trauma. Lin et al. reported a false-negative rate of 46.2 to $54.5 \%$ in hollow viscus perforation [33]. Similar results have been observed by Bhagvan et al., who described a sensitivity and specificity of 55.3 and $92.1 \%$, respectively [34•]. In diaphragmatic injuries, $82.1 \%$ sensitivity and $99.7 \%$ specificity have been reported [35]. Nevertheless, in their paper on traumatic diaphragmatic rupture, Mihos et al. achieved a correct preoperative diagnosis in only $26 \%$ of all patients, $74 \%$ being diagnosed intra-operatively [36].

Of note, with improvements in imaging techniques over the last decade, especially with $\mathrm{CT}$, conservative treatment has become more common in patients with blunt and penetrating trauma. While selective NOM has been considered the standard of care in blunt abdominal solid organ injuries [37, 38], its implementation in penetrating abdominal trauma has been considerably slower [10, 32, 39, 40].

In their 2001 report, Velmahos et al. [9] reported a $38 \%$ success rate for selective NOM of all patients admitted for penetrating trauma at a level 1 trauma center over 8 years. Negative laparotomy was performed in $9 \%$ of cases (as compared to $47 \%$ if treated by standard laparotomy). Delayed laparotomy was recorded in $4 \%$ and $0.3 \%$ had complications potentially related to the delay in laparotomy. Furthermore, these authors reported an estimated 3650-day reduction in hospital stay and overall $\$ 9,555,752$ savings in hospital charges compared with routine laparotomy. Of note, however, this study was performed at a high-volume center with a dedicated trauma team.

Similarly, in their analysis of 25,773 patients sustaining penetrating abdominal trauma between 2002 and 2008 in the USA, Zafar and colleagues [40] found an increasing use of NOM, resulting in a significant reduction in nontherapeutic laparotomy. An overall $20.2 \%$ rate of abdominal GSW and $33.9 \%$ of SW were treated conservatively. NOM failure occurred in $20.8 \%$ (GSW) and $15.2 \%$ (SW) respectively, leading to an increased mortality risk (4.48- and 9.83-fold increase, respectively; adjusted for demographics, injury severity, and clinical variables). 
Despite the advances in noninvasive diagnostics and the negative impact on outcome in case of failure, a substantial number of patients neither qualify for NOM nor present formal indications for urgent laparotomy: this group of patients might constitute an excellent indication for laparoscopic exploration.

Several surgical societies [16, 41-43] have recommended the use of laparoscopy for selected patients with blunt and penetrating abdominal trauma, either for screening, or as a diagnostic and therapeutic tool.

Apart from the reduction of additional surgical trauma, Taner et al. also described possible economic benefits, as nontherapeutic laparotomy was associated with a 1.78-fold increase in cost compared to exploration by laparoscopy [44].

\section{Prerequisites for Laparoscopy}

Prerequisites for laparoscopy are hemodynamic stability, absence of indications for urgent laparotomy, or intracranial trauma. Although one study [45] reported use of laparoscopy in hemodynamically unstable patients, hemodynamic instability and shock are generally considered as contraindications for laparoscopy [19, 46-48]. Other contraindications include diffuse peritonitis, evisceration, and penetrating anal or vaginal injuries [19, 46-48]. If intracranial injuries are suspected, pneumoperitoneum should only be established after careful evaluation, as abdominal carbon dioxide insufflation and increased intra-abdominal pressure can lead to elevated intracranial pressure (ICP) [49-51]. Multiple organ injuries have also been considered as limiting factors [48]. Sufficient training and experience of both the surgeon and trauma team, as well as infrastructural and economic measures, pose another challenge for routine use of trauma laparoscopy $[47 \bullet, 52]$.

\section{Indications for Laparoscopy}

As stated before, laparoscopy in trauma can be used for diagnosis and therapy in several indications, both in blunt and penetrating trauma:

1. Suspected hollow viscus injury (HVI) $[22,46,53 \bullet, 54$, 55•] - HVI occurs in about 0.9 to $2.5 \%$ of all trauma patients, predominantly involving the small bowel $[2,5$, 55•] (Fig. 1). In their retrospective analysis of more than 275,000 trauma admissions, Watts et al. [5] observed full thickness perforation in $41.5 \%$ of all patients with HVI. They also described a $27.6 \%$ morbidity and statistically significantly elevated mortality ( $19.8 \%$ with compared to $12.2 \%$ without HVI). In their 2003 report, Omori and colleagues [56] reported promising results in their therapeutic laparoscopic approach to isolated bowel rupture after blunt trauma. Despite nonstatistically significantly

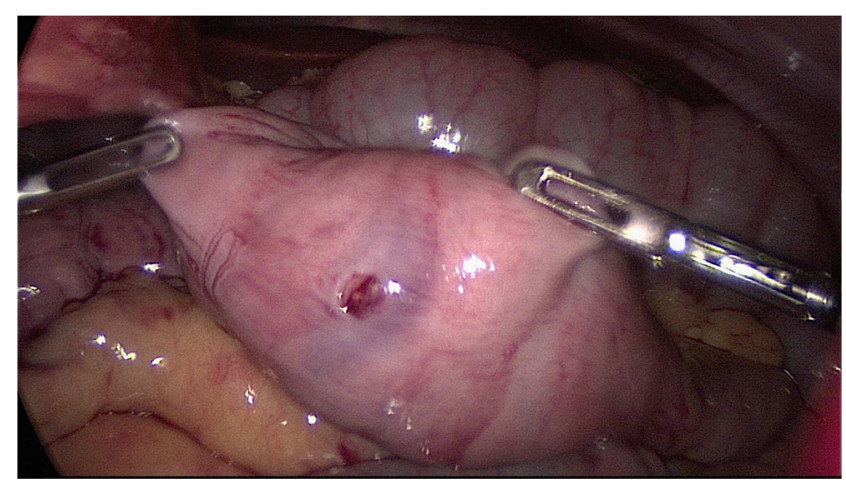

Fig. 1 Stab injury to the small bowel detected through diagnostic laparoscopy

longer operative times in laparoscopy as compared to laparotomy $(132 \pm 58.7$ vs. $143.6 \pm 27.3, p=.296)$, they described a statistically significant reduction in blood loss $(266.8 \pm 277.8 \mathrm{~mL}$ in laparotomy vs. $57.6 \pm 57.1 \mathrm{~mL}$ in laparoscopy, $p<.05$ ), no conversions and a similar duration of hospital stay.

2. Suspected diaphragmatic injury [21, 54]—Diaphragmatic injuries can be seen after penetrating thoraco-abdominal as well as blunt abdominal trauma. The importance of diaphragmatic repair has been underlined by Degiannis et al. [57], reporting a mortality rate of $25 \%$ after complications of delayed diagnosis as compared to $3 \%$ after early diaphragm repair. As radiological findings for diaphragmatic injuries may be equivocal, laparoscopic evaluation can clarify suspected injuries [58]. In their 10-year experience, Johnson et al. [53•] avoided a laparotomy in $89.3 \%$ of patients with laparoscopic evaluation and therapy in suspected diaphragmatic injury. Laparoscopic repair of diaphragmatic laceration was the most common procedure observed by Zafar et al. [47•] in their 2015 systematic review, accounting for $19.2 \%$ of all operations.

3. Free fluid of unknown source/suspected mesenteric laceration-Management strategies for the presence of free fluid without specific diagnosis of solid organ injury on CT $[33,59]$ include observation, DPL, diagnostic laparoscopy, and exploratory laparotomy [53•]. However, if a mesenteric injury is suspected, conservative management might be risky and it is important to check the perfusion of the respective bowel segment [53•] (Fig. 2). Mesenteric injuries in blunt trauma are relatively rare and occur mostly due to seatbelt restraint $[54,60 \bullet$. Delay in recognition of mesenteric injuries and possible consecutive bowel damage (by ischemia) can lead to devastating outcomes. As reported, CT sensitivity of 75 to $81 \%[29,61]$ leaves a certain degree of uncertainty. Laparoscopic exploration offers a sensitivity of 92 to $97.1 \%$ with a specificity of $100 \%[62,63]$.

4. "Unclear abdomen"-In case of significant discrepancy between clinical examination and imaging studies, as well 


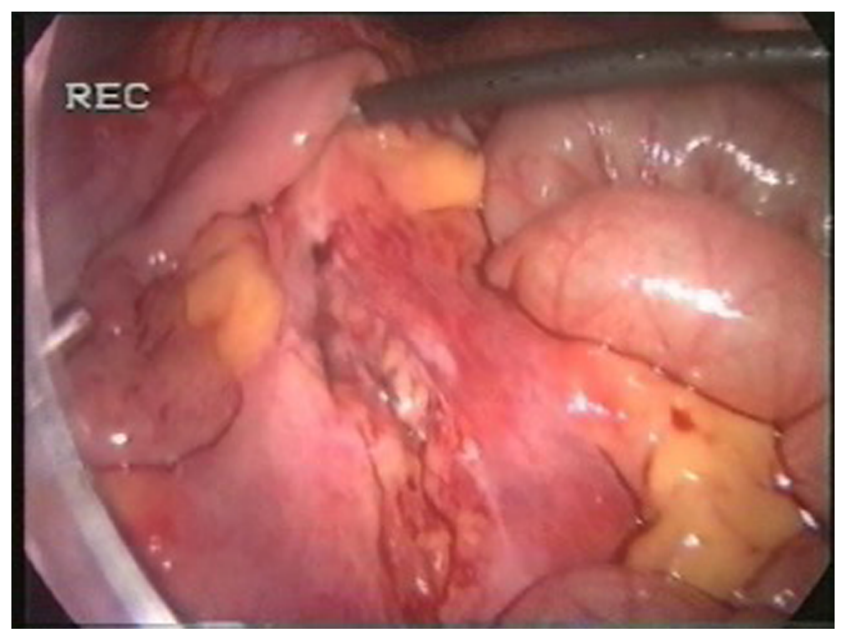

Fig. 2 Blunt abdominal trauma with mesenteric tear suspected on CT scan. Definitive diagnosis was made laparoscopically followed by laparoscopic suture repair once vascular integrity was checked

as diffuse and unspecific symptoms, exploratory laparoscopy can be used to identify possible causes (i.e., adhesions, internal hernia secondary to mesenteric laceration, volvulus) $[22,46,54]$.

5. In penetrating trauma with hemodynamic stability, the most common indications for laparoscopy are evaluation for diaphragmatic and intra-abdominal injury (e.g., free fluid of unknown source as discussed above) as well as screening for peritoneal violation in tangential stab and GSW [21, 42, 53•, 54].

As far as splenic injuries are concerned, the literature only mentions case reports of laparoscopic splenectomy and mesh splenorrhaphy; therefore, these operations are not supported by sound data [64-67]. From our point of view, splenic injuries are not an indication for laparoscopy for the following reasons: (I) stable patients with a splenic injury should undergo NOM and do not require surgery. (II) Unstable patients who remain so in spite of resuscitation require a trauma laparotomy; in these cases, laparoscopy is contraindicated. (III) Laparoscopic procedures on the spleen are usually undertaken with the patient in the right semilateral recumbent position, with the left arm fixed over the head. In trauma cases, however, this position can be counterproductive if more extensive surgeries become necessary.

The only exceptions for laparoscopy in splenic injury can be the fortuitous discovery of a minor splenic injury during laparoscopic exploration to exclude a diaphragmatic rupture or injury to the intestine or mesentery. In such cases, the concomitant splenic injury can be treated with fibrin adhesive or hemostyptic fleece. It must be emphasized that in this setting, the primary aim is not to treat the splenic injury but the other organ injuries; the splenic injury is sealed as a prophylactic measure to prevent further bleeding.

\section{Therapeutic laparoscopy}

Laparoscopy features a high therapeutic potential as several studies have reported successful interventions in blunt and penetrating trauma, thus further reducing the need for laparotomy [11] (Fig. 3a-d).

After implementation of exploratory laparoscopy for penetrating injuries, Kawahara et al. [63] reported a $73.3 \%$ reduction in laparotomy with definitive laparoscopic repair in $22.7 \%$ of cases. These authors proposed a standardized examination system, leading to no missed injuries with an accuracy of 98.7, $97.6 \%$ sensitivity, and $100 \%$ specificity. Chol et al. reported an $83 \%$ therapeutic rate with a $3.8 \%$ postoperative complication rate and no missed injuries [18]. In their systematic review of 51 studies on laparoscopy in penetrating injuries, O'Malley and colleagues [52] reported an overall therapeutic rate of $13.8 \%$ (ranging from 6.7 to $100 \%$ ) with a $3.2 \%$ missed injury rate. Diaphragmatic injuries accounted for $53.4 \%$ of all therapeutic laparoscopies. More recently, Zafar et al. [47•] found similar results in their analysis of the US National Trauma Data Bank data on 4755 patients undergoing diagnostic laparoscopy. Interventions were therapeutic in $19.3 \%$ of all patients and most often performed for diaphragmatic lacerations (19.2\%), gastrostomy $(14.4 \%)$, bowel repair $(15.6 \%)$ or resection $(11.8 \%)$, and splenectomy (5.2\%).

Promising results have also been reported in pediatric abdominal trauma. Marwan et al. [68] achieved a $90.5 \%$ successful diagnostic laparoscopy rate including $23.8 \%$ of patients undergoing to therapeutic laparoscopy. The $9.5 \%$ missed injury rate was due to delayed intervention several days after initial presentation. Li and colleagues [69•] conducted a meta-analysis of 64 studies (5 RCTs, 16 cohort studies, 43 case series) comparing laparoscopy to laparotomy; $76 \%$ of all included patient were successfully treated with laparoscopy. There was a significantly lower risk for postoperative complications (RR 0.37, $95 \%$ CI 0.29-0.46; $p<0.001)$ and a reduction in perioperative mortality ( $\mathrm{RR}$ $0.64,95 \%$ CI $0.52-0.80 ; p<0.001)$ in patients undergoing laparoscopy. Of note, however, only five studies were randomized; therefore, a selection bias in favor of laparoscopy cannot be excluded.

Conversion rates seem to depend strongly on the policies adopted in the respective hospitals, as some centers indicate routine laparotomy while others proceed to laparoscopy in comparable patients [33, 62]. Reported rates lie between 2.1 and $45 \%$ in penetrating $[62,70,71]$ and 8.5 to $50 \%$ in blunt trauma [33, 62]. Two recent systematic reviews $[47 \cdot, 53 \bullet]$ reported overall conversion rates of 10.7 and $20.2 \%$, respectively.

Another relevant topic routinely discussed in all laparoscopic procedures is the impact on duration of hospital stay. Several studies have reported statistically significant reductions as compared to open surgery. Lin et al. [33] observed a mean hospital stay of 11.0 days in laparoscopy 
Fig. 3 a Stab wound to the right upper quadrant; $\mathbf{b}$ view on abdomen: diagnostic laparoscopy confirmed the peritoneal penetration; c superficial hepatic laceration next to the gall bladder; d laparoscopic closure of the laceration
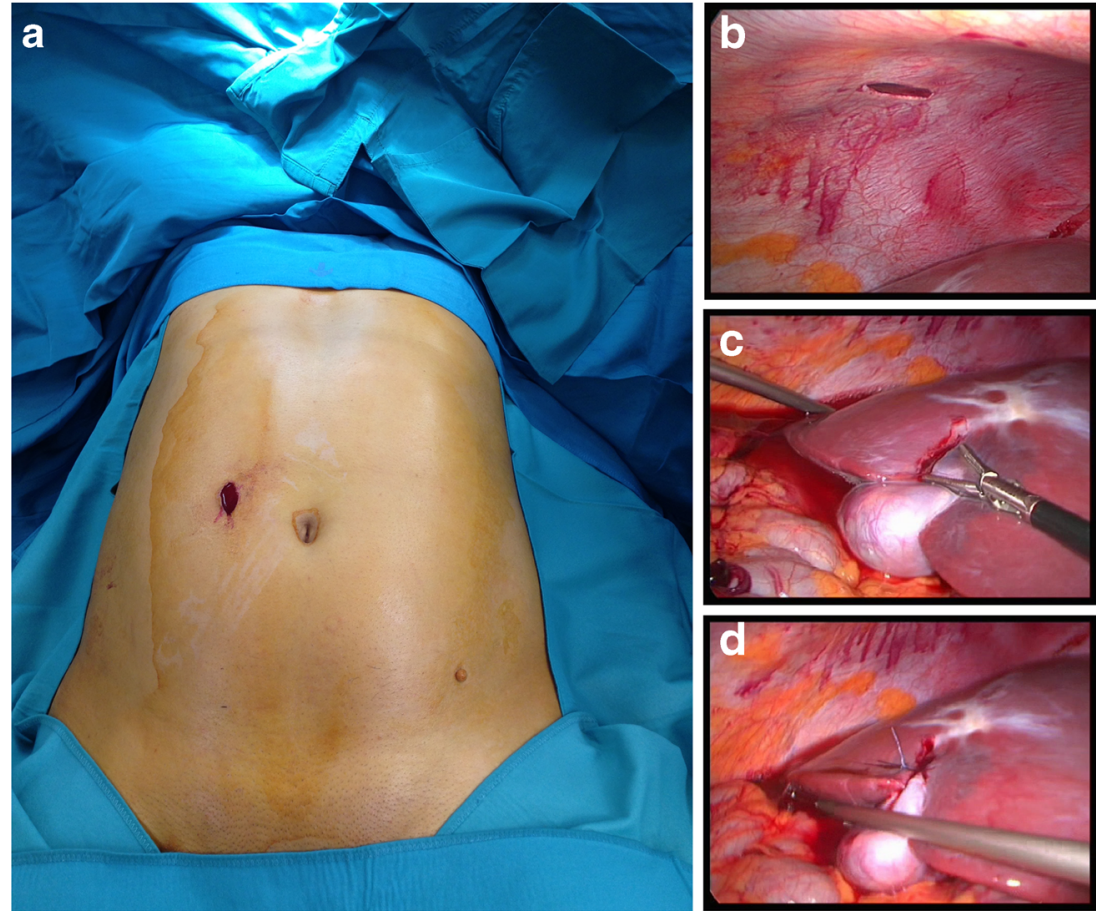

as compared to 17.6 days $(p<.001)$ after repair for blunt HVI and mesenteric trauma. Similar results (11 vs. 21 days; $p<0.001$ ) have been reported by Lee and colleagues [72]. A statistically significant reduction has also been reported in penetrating trauma (5.0 vs. 9.9 days; $p<0.001)[6,70]$. In their systematic review of 64 studies on blunt and penetrating trauma, Li et al. [69•] found a mean reduction in duration of hospital stay of 5.15 days (95\% CI -6.80 to $3.50 ; p<0.001$ ); however, adjustment for injury severity score was not performed, and hospital stays vary from country to country, according to hospital policies and cultural differences, leaving room for a potential selection bias.

\section{Complications of Trauma Laparoscopy}

Apart from the general risks related to laparoscopy (such as iatrogenic vascular and intestinal injuries), additional complications may be proper to trauma laparoscopy. First and foremost, missed injuries pose a serious risk, as delayed treatment can lead to increased morbidity and mortality. Early experiences have reported missed injury rates up to $77 \%$ in diagnostic laparoscopy [73]. These high rates, however, have been challenged by more recent data showing that missed injury rates are currently low, ranging between 0 and $3.2 \%$ $[18,33,47 \bullet, 52,53 \bullet, 63,74]$.
Development of (tension-) pneumothorax in patients with diaphragmatic injury has been described [74, 75]. Although rare, a high index of suspicion should lead to correct diagnosis, if patient status deteriorates during laparoscopy for trauma without any other obvious reason. Venous gas embolism is another reported complication of laparoscopy in general [76]. Although to the best of our knowledge there have not been any reports of this complication in trauma laparoscopy, gas embolism could possibly occur especially when venous injury is present. Due to trans-peritoneal absorption of carbon dioxide elevated ICP (see above) and acidosis may occur [18, $51,77]$, the latter being one proponent of the infamous "trauma triad of death" [78].

\section{Technique}

Patients should be prepared and positioned in the same way as for trauma laparotomy, allowing rapid conversion to open surgery and access to the whole trunk, whenever necessary. Surgical instruments for open surgery should be readily at hand. Furthermore, patients should be securely fixed to the operating table, as intraoperative tilting to shift the intra-abdominal organs might be necessary [18].

To minimize the risk of missed injuries, a systematic approach for evaluation of the abdomen should be used [79]. As described previously [22, 46], one possible approach for diagnostic and therapeutic laparoscopy 
Fig. 4 Trocar sites for diagnostic laparoscopy. Staggering the flank trocars slightly cranial and caudal of the umbilicus enables better exploration with less instrument collision

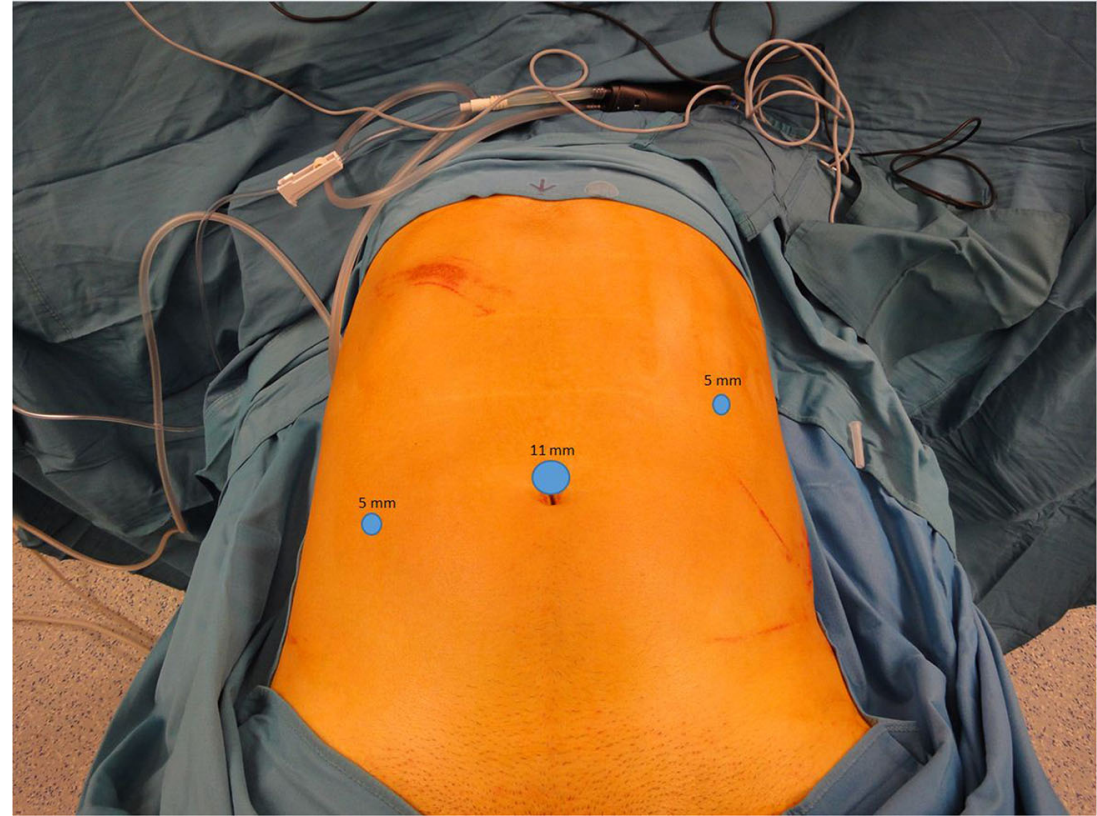

could be the following: the initial trocar $(5 / 10 / 11 \mathrm{~mm})$ is inserted at the umbilicus via the open method [80•]. Pneumoperitoneum is established slowly and cautiously. After initial inspection of the abdominal cavity, two more working trocars $(5-10 \mathrm{~mm})$ are placed (Fig. 4).

The abdomen is evaluated for possible additional injuries, starting from the right upper quadrant, systematically in a clockwise manner. The liver, spleen, and diaphragm are evaluated with the patient in the reverse Trendelenburg position; the surgeon then inspects the splenic flexure, descending and sigmoid colons toward the pelvis, runs over to the right lower quadrant and then the cecum and ascending colon. Then, patients are positioned in the Trendelenburg position to examine the rectum, Douglas' space, bladder, and pelvic organs. The position of the omentum is shifted cranially to enable evaluation of the small bowel. Starting in the ileocecal region, the intestines are examined in the oral direction to the Treitz ligament with the assistance of two atraumatic forceps. The lesser sac may be opened to evaluate the duodenum, posterior gastric wall, and pancreas. However, this procedure is performed only when injury of these organs is suspected.

Laparoscopic treatment depends on surgeon skills and the availability of equipment. Simple lacerations may be sutured using 3/0 monofilament material. However, resection is required when larger injuries of the hollow organs are present. Continuity can be restored rapidly and safely with stapled anastomoses. Diaphragmatic injuries may be repaired depending on their size, by sutures or appropriate prosthetic materials. Hemostasis can be achieved by using coagulation, hemoclips, or sutures. Large wound surfaces and lacerations of the solid organs may be treated rapidly and effectively using tamponade with gauze sponges and fibrin glue or with new hemostatic agents alone (e.g., Floseal®, Hemopatch () . If severe bleeding is present or adequate visualization is not possible, conversion to an open approach should not be delayed.

\section{Conclusion}

Management of abdominal trauma remains a challenging field for the trauma personnel. The ambitious goal of minimizing aggressive procedures and related morbidities has to be weighed against the potential consequences of delayed treatment of missed injuries. As a complement to NOM, laparoscopy can play an important role in diagnosis and treatment of blunt and penetrating trauma in hemodynamically stable patients. Low missed injury rates, reduced duration of hospital stay, faster recovery, and reduced cost make it an attractive and safe alternative to classical trauma laparotomy. However, as stated by Zafer et al. [47•] surgeon experience and skill as well as sufficient staffing and equipment are key factors for successful implementation of laparoscopy in routine trauma management.

\section{Compliance with Ethical Standards}

Conflict of Interest The authors declare that they have no conflict of interest

Human and Animal Rights and Informed Consent This article does not contain any studies with human or animal subjects performed by any of the authors. 


\section{References}

Papers of particular interest, published recently, have been highlighted as:

- Of importance

1. Soreide K. Epidemiology of major trauma. Br J Surg. 2009;96(7): 697-8. doi:10.1002/bjs.6643.

2. Smith J, Caldwell E, D'Amours S, et al. Abdominal trauma: a disease in evolution. ANZ J Surg. 2005;75(9):790-4. doi:10.1111 jj.1445-2197.2005.03524.x.

3. Champion HR, Copes WS, Sacco WJ, et al. The Major Trauma Outcome Study: establishing national norms for trauma care. J Trauma. 1990;30(11):1356-65.

4. Lefering R, Nienaber U (2015) Annual Report 2015 TraumaRegister DGU. http://www.traumaregister-dgu. de/fileadmin/user_upload/traumaregister-dgu. de/docs/Downloads/TR-DGGU-Jahresbericht 2015.pdf. Accessed 22 May 2016.

5. Watts DD, Fakhry SM. Incidence of hollow viscus injury in blunt trauma: an analysis from 275,557 trauma admissions from the East multi-institutional trial. J Trauma. 2003;54(2):289-94. doi:10.1097 101.TA.0000046261.06976.6A.

6. Sosa JL, Baker M, Puente I, et al. Negative laparotomy in abdominal gunshot wounds: potential impact of laparoscopy. J Trauma. 1995;38(2):194-7.

7. Leppaniemi A, Salo J, Haapiainen R. Complications of negative laparotomy for truncal stab wounds. J Trauma. 1995;38(1):54-8.

8. Renz BM, Feliciano DV. Unnecessary laparotomies for trauma: a prospective study of morbidity. J Trauma. 1995;38(3):350-6.

9. Velmahos GC, Demetriades D, Toutouzas KG, et al. Selective nonoperative management in 1,856 patients with abdominal gunshot wounds: should routine laparotomy still be the standard of care? Ann Surg. 2001;234(3):395-402. discussion 402-3.

10. Ryzoff RI, Shaftan GW, Herbsman H. Selective conservatism in penetrating abdominal trauma. Surgery. 1966;59(4):650-3.

11. Zantut LF, Ivatury RR, Smith RS, et al. Diagnostic and therapeutic laparoscopy for penetrating abdominal trauma: a multicenter experience. J Trauma. 1997;42(5):825-9. discussion 829-31.

12. Short AR. The uses of coelioscopy. Br Med J. 1925;2(3371):254-5.

13. Heselson $J$. The value of peritoneoscopy as a diagnostic aid in abdominal conditions. Cent Afr J Med. 1963;9:395-8.

14. Heselson J. Peritoneoscopy in abdominal trauma. S Afr J Surg. 1970;8(3):53-61.

15. Biffl WL, Leppaniemi A. Management guidelines for penetrating abdominal trauma. World J Surg. 2015;39(6):1373-80. doi:10.1007 /s00268-014-2793-7. Based on comprehensive literature review the authors propose algorithms for the management of penetrating abdominal trauma, taking into account the different anatomic regions and specific injury patterns.

16. Hori Y. Diagnostic laparoscopy guidelines: this guideline was prepared by the SAGES guidelines committee and reviewed and approved by the board of governors of the Society of American Gastrointestinal and Endoscopic Surgeons (SAGES), November 2007. Surg Endosc. 2008;22(5):1353-83. doi:10.1007/s00464008-9759-5.

17. Sauerland S, Agresta F, Bergamaschi R, et al. Laparoscopy for abdominal emergencies: evidence-based guidelines of the European Association for Endoscopic Surgery. Surg Endosc. 2006;20(1):14-29. doi:10.1007/s00464-005-0564-0.

18. Chol YB, Lim KS. Therapeutic laparoscopy for abdominal trauma. Surg Endosc. 2003;17(3):421-7. doi:10.1007/s00464-002-8808-8.

19. Biffl WL, Kaups KL, Cothren CC, et al. Management of patients with anterior abdominal stab wounds: a Western Trauma
Association multicenter trial. J Trauma. 2009;66(5):1294-301. doi:10.1097/TA.0b013e31819dc688.

20. Rosenthal RE, Smith J, Walls RM, et al. Stab wounds to the abdomen: failure of blunt probing to predict peritoneal penetration. Ann Emerg Med. 1987;16(2):172-4.

21. Uranues S, Popa DE, Diaconescu B, et al. Laparoscopy in penetrating abdominal trauma. World J Surg. 2015;39(6):1381-8. doi:10.1007/s00268-014-2904-5.

22. Uranues S, Dorr K. Laparoscopy in abdominal trauma. Eur J Trauma Emerg Surg. 2010;36(1):19-24. doi:10.1007/s00068-0109219-5.

23. Catre MG. Diagnostic peritoneal lavage versus abdominal computed tomography in blunt abdominal trauma: a review of prospective studies. Can J Surg. 1995;38(2):117-22.

24. Sriussadaporn S, Pak-art R, Pattaratiwanon M, et al. Clinical uses of diagnostic peritoneal lavage in stab wounds of the anterior abdomen: a prospective study. Eur Surg Acta Chir. 2002;168(8-9):490 3. doi:10.1080/110241502321116514.

25. Wood D, Berci G, Morgenstern L, et al. Mini-laparoscopy in blunt abdominal trauma. Surg Endosc. 1988;2(3):184-9.

26. Rozycki GS, Ballard RB, Feliciano DV, et al. Surgeon-performed ultrasound for the assessment of truncal injuries: lessons learned from 1540 patients. Ann Surg. 1998;228(4):557-67.

27. Natarajan B, Gupta PK, Cemaj S, et al. FAST scan: is it worth doing in hemodynamically stable blunt trauma patients? Surgery. 2010;148(4):695-700. doi:10.1016/j.surg.2010.07.032. discussion $700-1$.

28. Udobi KF, Rodriguez A, Chiu WC, et al. Role of ultrasonography in penetrating abdominal trauma: a prospective clinical study. J Trauma. 2001;50(3):475-9.

29. Killeen KL, Shanmuganathan K, Poletti PA, et al. Helical computed tomography of bowel and mesenteric injuries. J Trauma. 2001;51(1):26-36.

30. Shanmuganathan K, Mirvis SE, Chiu WC, et al. Penetrating torso trauma: triple-contrast helical CT in peritoneal violation and organ injury-a prospective study in 200 patients. Radiology. 2004;231(3):775-84. doi:10.1148/radiol.2313030126.

31. Holmes JF, McGahan JP, Wisner DH. Rate of intra-abdominal injury after a normal abdominal computed tomographic scan in adults with blunt trauma. Am J Emerg Med. 2012;30(4):574-9. doi:10.1016/j.ajem.2011.02.016.

32. Velmahos GC, Constantinou C, Tillou A, et al. Abdominal computed tomographic scan for patients with gunshot wounds to the abdomen selected for nonoperative management. J Trauma. 2005;59(5): 1155-60. discussion 1160-1.

33. Lin HF, Chen YD, Lin KL, et al. Laparoscopy decreases the laparotomy rate for hemodynamically stable patients with blunt hollow viscus and mesenteric injuries. Am J Surg. 2015;210(2):326-33. doi:10.1016/j.amjsurg.2014.11.009.

34. Bhagvan S, Turai M, Holden A, et al. Predicting hollow viscus injury in blunt abdominal trauma with computed tomography. World J Surg. 2013;37(1):123-6. doi:10.1007/s00268-012-17983. This study retrospectively reevaluated CT scans for hollow viscus injury in patients with suspected abdominal injuries and subsequent exploration by laparotomy. Correlating CT with operative finding, they described a $55.3 \%$ sensitivity and 92.06 \% specificity of $\mathrm{CT}$ in predicting hollow viscus injury. Thus CT alone does not qualify as a stand-alone screening tool for hollow viscus injuries.

35. Stein DM, York GB, Boswell S, et al. Accuracy of computed tomography $(\mathrm{CT})$ scan in the detection of penetrating diaphragm injury. J Trauma. 2007;63(3):538-43. doi:10.1097/TA.0b013 e318068b53c.

36. Mihos P, Potaris K, Gakidis J, et al. Traumatic rupture of the diaphragm: experience with 65 patients. Injury. 2003;34(3):169-72. doi:10.1016/S0020-1383(02)00369-8. 
37. Giannopoulos GA, Katsoulis IE, Tzanakis NE, et al. Non-operative management of blunt abdominal trauma. Is it safe and feasible in a district general hospital? Scand J Trauma Resusc Emerg Med. 2009;17:22. doi:10.1186/1757-7241-17-22.

38. Schroeppel TJ, Croce MA. Diagnosis and management of blunt abdominal solid organ injury. Curr Opin Crit Care. 2007;13(4): 399-404. doi:10.1097/MCC.0b013e32825a6a32.

39. Okus A, Sevinc B, Ay S, et al. Conservative management of abdominal injuries. Ulus Cerrahi Derg. 2013;29(4):153-7. doi:10.5152/UCD.2013.2300.

40. Zafar SN, Rushing A, Haut ER, et al. Outcome of selective nonoperative management of penetrating abdominal injuries from the North American National Trauma Database. Br J Surg. 2012;99 Suppl 1:155-64. doi:10.1002/bjs.7735.

41. Agresta F, Ansaloni L, Baiocchi GL, et al. Laparoscopic approach to acute abdomen from the Consensus Development Conference of the Societa Italiana di Chirurgia Endoscopica e nuove tecnologie (SICE), Associazione Chirurghi Ospedalieri Italiani (ACOI), Societa Italiana di Chirurgia (SIC), Societa Italiana di Chirurgia d'Urgenza e del Trauma (SICUT), Societa Italiana di Chirurgia nell'Ospedalita Privata (SICOP), and the European Association for Endoscopic Surgery (EAES). Surg Endosc. 2012;26(8):2134 64. doi:10.1007/s00464-012-2331-3.

42. Como JJ, Bokhari F, Chiu WC, et al. Practice management guidelines for selective nonoperative management of penetrating abdominal trauma. J Trauma. 2010;68(3):721-33. doi:10.1097/TA.0b013 e3181cf7d07.

43. Redmond HP, Andrews E, Hill DK (2005) Diagnostic Laparoscopy - clinical guidelines. https://www.rcsi. ie/files/surgery/docs/20101221085858_7433\%20RCSI\%20 Laparoscopy\%20Guide.pd.pdf. Accessed $2 \overline{6}$ May 2016.

44. Taner AS, Topgul K, Kucukel F, et al. Diagnostic laparoscopy decreases the rate of unnecessary laparotomies and reduces hospital costs in trauma patients. J Laparoendosc Adv Surg Tech A. 2001;11(4):207-11. doi:10.1089/109264201750539718.

45. Cherkasov M, Sitnikov V, Sarkisyan B, et al. Laparoscopy versus laparotomy in management of abdominal trauma. Surg Endosc. 2008;22(1):228-31. doi:10.1007/s00464-007-9550-z.

46. Uranues S, Fingerhut A. Trauma laparotomy: indications, priorities, and damage control. In: Oestern H, Trentz OL, Uranues S, editors. Head, thoracic, abdominal, and vascular injuries: trauma surgery I. Berlin: Springer; 2011. p. 333-42.

47. Zafar SN, Onwugbufor MT, Hughes K, et al. Laparoscopic surgery for trauma: the realm of therapeutic management. Am J Surg. 2015;209(4):627-32. doi:10.1016/j.amjsurg.2014.12.011. In this retrospective analysis of 4,755 patients who underwent a diagnostic laparoscopy, the authors report a $19.3 \%$ therapeutic laparoscopic intervention rate. Furthermore they show the most common indications as well as missed injury and conversion rates, among this set of patients recruited from the US National Trauma Data Bank.

48. Goettler CE, Bard, Toschlog EA. Laparoscopy in trauma. Curr Surg. 2004;61(6):554-9. doi:10.1016/j.cursur.2004.06.017.

49. Kamine TH, Elmadhun NY, Kasper EM, et al. Abdominal insufflation for laparoscopy increases intracranial and intrathoracic pressure in human subjects. Surg Endosc. 2015. doi:10.1007/s00464015-4715-7.

50. Josephs LG, Este-McDonald JR, Birkett DH, et al. Diagnostic laparoscopy increases intracranial pressure. J Trauma. 1994;36(6): 815-8. discussion 818-9.

51. Mobbs RJ, Yang MO. The dangers of diagnostic laparoscopy in the head injured patient. J Clin Neurosci. 2002;9(5):592-3. doi:10.1054/jocn.2001.1070.

52. O'Malley E, Boyle E, O'Callaghan A, et al. Role of laparoscopy in penetrating abdominal trauma: a systematic review. World J Surg. 2013;37(1):113-22. doi:10.1007/s00268-012-1790-y.
53. Johnson JJ, Garwe T, Raines AR, et al. The use of laparoscopy in the diagnosis and treatment of blunt and penetrating abdominal injuries: 10-year experience at a level 1 trauma center. Am J Surg. 2013;205(3):317-20. doi:10.1016/j.amjsurg.2012.10.021. In this single center report, the authors showed the potential for reductions in unnecessary laparotomies by implementation of laparoscopic evaluation in certain indications. Comparing their 10 year experience of MAS in abdominal trauma to previous data, $89.3 \%$ of laparotomies were avoided since the implementation of MAS in abdominal trauma.

54. Nicolau AE. Is laparoscopy still needed in blunt abdominal trauma? Chir (Bucur). 2011;106(1):59-66.

55. Chichom Mefire A, Weledji PE, Verla VS, et al. Diagnostic and therapeutic challenges of isolated small bowel perforations after blunt abdominal injury in low income settings: analysis of twenty three new cases. Injury. 2014;45(1):141-5. doi:10.1016/j. injury.2013.02.022. This prospective case series investigated the challenges in diagnosing and treatment of isolated small bowel perforation in an economically restricted setting. They reported a $69.6 \%$ delayed diagnosis rate of isolated small bowel injuries and stressed the importance of awareness of these rare but potentially fatal injuries paired with a wellbalanced use of the different possible diagnostic and therapeutic modalities.

56. Omori H, Asahi H, Inoue Y, et al. Selective application of laparoscopic intervention in the management of isolated bowel rupture in blunt abdominal trauma. J Laparoendosc Adv Surg Tech A. 2003;13(2):83-8. doi:10.1089/109264203764654696.

57. Degiannis E, Levy RD, Sofianos C, et al. Diaphragmatic herniation after penetrating trauma. Br J Surg. 1996;83(1):88-91.

58. Friese RS, Coln CE, Gentilello LM. Laparoscopy is sufficient to exclude occult diaphragm injury after penetrating abdominal trauma. J Trauma. 2005;58(4):789-92.

59. Banz VM, Butt MU, Zimmermann H, et al. Free abdominal fluid without obvious solid organ injury upon CT imaging: an actual problem or simply over-diagnosing? J Trauma Manag Outcomes. 2009;3:10. doi:10.1186/1752-2897-3-10.

60. Kordzadeh A, Melchionda V, Rhodes KM, et al. Blunt abdominal trauma and mesenteric avulsion: a systematic review. Eur J Trauma Emerg Surg. 2015. doi:10.1007/s00068-015-0514-z. This literature review focused on the rare entity of mesenteric avulsion in blunt abdominal trauma. Analyzing 20 cases reported over a period of 63 years, the authors identified seat belt restraint as the mechanism of injury in $60 \%$.

61. Matsushima K, Mangel PS, Schaefer EW, et al. Blunt hollow viscus and mesenteric injury: still underrecognized. World J Surg. 2013;37(4):759-65. doi:10.1007/s00268-012-1896-2.

62. Kaban GK, Novitsky YW, Perugini RA, et al. Use of laparoscopy in evaluation and treatment of penetrating and blunt abdominal injuries. Surg Innov. 2008;15(1):26-31. doi:10.1177 $/ 1553350608314664$.

63. Kawahara NT, Alster C, Fujimura I, et al. Standard examination system for laparoscopy in penetrating abdominal trauma. J Trauma. 2009;67(3):589-95. doi:10.1097/TA.0b013e3181a60593.

64. Uranues S, Kilic YA. Injuries to the Spleen. Eur J Trauma Emerg Surg. 2008;34(4):355. doi:10.1007/s00068-008-8102-0.

65. Ayiomamitis GD, Alkari B, Owera A, et al. Emergency laparoscopic splenectomy for splenic trauma in a Jehovah's Witness patient. Surg Laparosc Endosc Percutan Tech. 2008;18(6):626-30. doi:10.1097/SLE.0b013e31818133c6.

66. Koehler RH, Smith RS, Fry WR. Successful laparoscopic splenorrhaphy using absorbable mesh for grade III splenic injury: report of a case. Surg Laparosc Endosc. 1994;4(4):311-5.

67. Agarwal N. Laparoscopic splenectomy in a case of blunt abdominal trauma. J Minim Access Surg. 2009;5(3):78-81. doi:10.4103/09729941.58503. 
68. Marwan A, Harmon CM, Georgeson KE, et al. Use of laparoscopy in the management of pediatric abdominal trauma. J Trauma. 2010;69(4):761-4. doi:10.1097/TA.0b013e3181c81d97.

69. Li Y, Xiang Y, Wu N, et al. A comparison of laparoscopy and laparotomy for the management of abdominal trauma: a systematic review and meta-analysis. World J Surg. 2015;39(12):2862-71. doi:10.1007/s00268-015-3212-4. This Meta-analysis of 64 studies (of which five were randomized controlled) included 9,058 patients. Comparing management of abdominal trauma by laparoscopy to laparotomy, they found reductions in complication rates, perioperative mortality and duration of hospital stay with a $1 \%$ missed injury rate and a $24 \%$ conversion rate.

70. Lin HF, Wu JM, Tu CC, et al. Value of diagnostic and therapeutic laparoscopy for abdominal stab wounds. World J Surg. 2010;34(7): 1653-62. doi:10.1007/s00268-010-0485-5.

71. Ahmed N, Whelan J, Brownlee J, et al. The contribution of laparoscopy in evaluation of penetrating abdominal wounds. J Am Coll Surg. 2005;201(2):213-6. doi:10.1016/j.jamcollsurg.2005.04.021.

72. Lee PC, Lo C, Wu JM, et al. Laparoscopy decreases the laparotomy rate in hemodynamically stable patients with blunt abdominal trauma. Surg Innov. 2014;21(2):155-65. doi:10.1177 $/ 1553350612474496$.

73. Villavicencio RT, Aucar JA. Analysis of laparoscopy in trauma11No competing interests declared. J Am Coll Surg. 1999;189(1):11-20. doi:10.1016/S1072-7515(99)00052-6.
74. Fabian TC, Croce MA, Stewart RM, et al. A prospective analysis of diagnostic laparoscopy in trauma. Ann Surg. 1993;217(5):557-64. discussion 564-5.

75. Ivatury RR, Simon RJ, Stahl WM. A critical evaluation of laparoscopy in penetrating abdominal trauma. J Trauma. 1993;34(6):8227. discussion 827-8.

76. Cottin V, Delafosse B, Viale J. Gas embolism during laparoscopy. Surg Endosc. 1996;10(2):166-9. doi:10.1007/BF00188365.

77. Kwak HJ, Jo YY, Lee KC, et al. Acid-base alterations during laparoscopic abdominal surgery: a comparison with laparotomy. Br J Anaesth. 2010;105(4):442-7. doi:10.1093/bja/aeq185.

78. Mikhail J. The trauma triad of death: hypothermia, acidosis, and coagulopathy. AACN Clin Issues. 1999;10(1):85-94.

79. Gorecki PJ, Cottam D, Angus LD, et al. Diagnostic and therapeutic laparoscopy for trauma: a technique of safe and systematic exploration. Surg Laparosc Endosc Percutan Tech. 2002;12(3):195-8.

80. Uranues S, Ozkan OV, Tomasch G. Safe and easy access technique for the first trocar in laparoscopic surgery. Langenbecks Arch Surg. 2016. doi:10.1007/s00423-016-1474-4. In this article the authors report their experience with an open approach for safe and quick positioning of the first trocar in (trauma) laparotomy. They described a $0.09 \%$ of accidental injuries after open access as compared to $0.9 \%$ after blind puncture by Veress needle. 